\title{
Sensitivity and Specificity of Rapid Diagnostic Test with Microscopic Gold Standard to Identify Plasmodium Species
}

\author{
Sahrir Sillehu ${ }^{1}$, Heny Arwati ${ }^{2}$, Yoes Prijatna Dachlan ${ }^{3}$, Sudjajadi Keman ${ }^{4}$ \\ ${ }^{1,4}$ Faculty of Public Health, Airlangga University, Surabaya, Indonesia \\ ${ }^{2,3}$ Faculty of Medicine, Airlangga University, Surabaya Indonesia
}

\begin{tabular}{l}
\hline \hline Article Info \\
\hline Article history: \\
Received Feb 25, 2016 \\
Revised May 20, 2016 \\
Accepted May 26, 2016
\end{tabular}

Keyword:

Microscopic malaria Rapid Diagnostic Test Sensitivity Specificity

\begin{abstract}
Malaria is a main health problem in islands area which is under developed and isolated. Nation-wide, in 2014 Maluku province was recorded to have Annual Malaria Incident (AMI) value of $30.4 \%$, positive incidents of $13.30 \%$, ABER $3.76 \%$, SPR $21.50 \%$, and Annual Parasite Incident (API) $8.10 \%$, while South Buru Regency has a value of Annual Malaria Incident (AMI) of $14.49 \%, 494$ positive incidents, ABER 1.12\%, SPR $60.91 \%$, and Annual Parasite Incident (API) $6.86 \%$. The purpose of this study was to identify Plasmodium species in malaria incidents in Namrole Subdistrict, South Buru Regency, Maluku Province. Observational research with a sample of 64 respondents for symptomatic and asymptomatic malaria. The instrument for the research was Rapid Diagnostic Test (RDT) and microscopic Gold Standard. Result: Malaria examination by using RDT suggested 3 kinds of parasites, i.e., P. falciparum, P. Vivax, and a mix between P. falciparum and P. vivax. Most parasites found were P. falciparum $56.3 \%$. The accuracy of RDT examination was proven with microscopic test and the result suggested that the RDT sensitivity was $100 \%$ and the specificity was $63.3 \%$. Positive predictive value was $92.9 \%$ and negative predictive value was $100 \%$, both were for positive likelihood ration of $2.75 \%$. While for negative likelihood ration of $0 \%$, the value of degree of conformity (Kappa) between RDT and microscopic is 0\%. RDT has one benefit that it can be use to conduct malaria diagnosis rapidly, particularly in isolated areas. The benefit of Rapid Diagnostic Test (RDT) was that it could be used in remote and isolated areas to conduct diagnosis. RDT is highly effective and efficient.
\end{abstract}

Copyright @ 2016 Institute of Advanced Engineering and Science. All rights reserved.

Corresponding Author:

Sahrir Sillehu,

Doctoral Student at Faculty of Public Health,

Airlangga University,

Campus C UNAIR, Mulyorejo, Surabaya, Indonesia.

Email: umay_01@yahoo.com

\section{INTRODUCTION}

Malaria is a type of infection caused by protozoa from Plasmodium genus. Malaria is an infectious disease which is very dominant in tropical and sub tropical areas. It can cause millions of death annually. Based on information and profiles of 99 countries worldwide, the controlling and elimination of Malaria incidents has progressing globally. As many as 80 countries are currently in supervision phase, while 19 others are in pre-elimination phase of malaria. It is estimated that 3.3 billion people around the globe are in a risk of getting infected by malaria. In Africa, the risk of getting infected by malaria is around $81 \%$ case, it is estimated that $91 \%$ mortalities occur on children aged under 5 years and pregnant woman [1].

In Indonesia, Malaria is one of the indicators of the targets of Millennium Development Goals (MDGs), i.e., stopping the spread and reducing malaria incidents in 2015. This can be indicated from the 
decrease of morbidity and mortality caused by malaria. Global Malaria Programme (GMP) stated that malaria is an ilness that must be continuously observed, monitored, and evaluated and it takes a formulation of appropriate policies and strategies [2].

Staid that the increasing incidents of malaria from year to year and the occurrence of Malaria Extraordinary Incidents during the period of 1997-2000 were caused by some factors including: 1). environmental change leading to wider area for malaria breedings), 2) high people mobility, 3) rain season changes, it has been much longer than dry season in the recent years, 4) lingering economic crisis bringing about malnutrition in some areas that they become adverse to malaria exposure, 5) low level of concern from the society to contributr in the efforts of preventing and mitigating malaria [3].

Indonesia is a country still facing the risk of malaria, some $80 \%$ of regencies/towns in Indonesia cam be included into malaria endemic category. Malaria attacks people domiciling in remote areas with poor environmental condition, hard to reach transportation and communication, and limited access to health facilities. The number of reported clinical incidents in 2009 were as many as 1,143,024 people with positife case, based in laboratory examination were 199,577 people. Regarding mortality of infectious and non infectious disease, malaria ranks number 6 (4.6\%) [4].According to the data of Ministry of Health of Republic of Indonesia, generally malaria sufferers in Indonesia are inhabitants of remote and hard to reach areas, and live in poverty. On top of that, from 1998 to 2003, the occurrences of Extraordinary Incidents (KLB) included 14 provinces and 26 regencies in 162 villages with the number of sufferres of 27,956 people and 328 mortalities) [5].

The development of malaria program in Maluku Province from 2011-2014 suggested the following; in 2011 the number of malaria declared as positively suffering malaria per 1,000 citizen was as many as 13.857\%, ABER 2.37\%, SPR 34.48\%, API 8.10\% In 2012; positive incidents $16.69 \%$, ABER 2.62\%, SPR 37.64\%, API 9.86\%. In 2013; positive incidents 16.508\%, ABER 3.32\%, SPR 29.34\%, API 9.76\%. In 2014; positive incidents $13.307 \%$, ABER 3.76\%, SPR 21.50\%, API 8.10\% (Health Profile, 2014) [6].

South Buru Regency in 011, the number of positive incidents of malria was as many as 477, ABER $0.91 \%$, SPR $72.49 \%$, API $6.63 \%$. In 2012; positive incidents 208, ABER 0.53\%, SPR 54.02\%, API 2.89\%. In 2013; positive incidents 361, ABER 0.69\%, SPR 71.91\%, API 5.01\%. In 2014; positive incidents 494, ABER $1.12 \%$, SPR $60.91 \%$, API $6.86 \%$ [7].

In South Buru regency, there are some isolated people inhabiting mountainous or inland areas with limited infrastructures. These people still live primitively and do not do many interactions with modern people life. While their daily life depends on the surrounding natures or they live vegetatively so to say. If any member of their families suffers from malaria, they will attempt to cure them with traditional ingredients taken from natural herbs around them [8].

Clinical manifestations which are specifically found in malaria endemic areas, which can be used as initial step in diagnosing clinical malaria, are very helpful in rapid, appropriate, and rational diagnosis of malaria, however, clinical malaria diagnosis must be confirmed with the result of microscopic test, which remains a gold standard in diagnosing malaria. Lacking of workforce in the field of laboratory technicians skilled enough in using microscope to properly diagnose malaria is one of the factors leading to slow medication and inappropriate malaria diagnosis [9].

Mobility or movement of inhabitants from malaria endemic areas to non endemic areas, inhabitants traveling and coming home for certain period of time (incubation period) of Plasmodium, potentially lead to the transmission or infection of malaria. People's migration bring about the movement of population infected by P. falciparum, especially in children. Some reports mentioned that Multiplicity of Infection (MOI) will reflect individuals infected by having immunity against malaria [10].

According to the WHO, RDT is alternative method based dipstick major clinical manifestations of malaria, especially in places that do not have a qualified technician and microscopic means. In addition, helpful RDT unit emergency medical services, when extraordinary event malaria, as well as in areas that are very difficult and disadvantaged are not available clinical laboratory facilities [11].

This research aimed to know the sensitivity and specificity of Rapid Diagnostic Test with Microscopic as gold stadard in conducting diagnosis of malaria incidents in Namrole Subdistrict, South Buru Regency, Maluku Province.

\section{RESEARCH METHOD}

Based on the type, this research is an observational research which was conducted in Namrole subdistrict, South Buru Regency, Maluku Province. The samples used in this research were as many as 64 respondents with symptomatic and asymptomatic malaria. The tool used in this research was Rapid Diagnostic Test (RDT) and Microscopic as Gold Standard [12-16]. Data gathering technique was conducted by taking blood samples in all age groups, which is then continued with blood checking to detect the 
presence of parasitic species of Plasmodium by using Rapid Diagnostic Tool (RDT) and Microscopic as Gold Standard for sensitivity and specificity test.

\section{RESULTS AND ANALYSIS}

Table 1 showes that most of malaria infection was occurred toward children in the age of 0-10 years old in 39 respondents $(60.9 \%)$, meanwhile, the age group of 21-30 years old and 31-40 years old were 9 respondents $(14.1 \%)$.

Table 1. Distribution of Frequency Based on Age Group $(n=64)$

\begin{tabular}{lcc}
\hline \multicolumn{1}{c}{ Age Group } & $\mathrm{N}$ & $\%$ \\
\hline $0-10$ years old & 39 & 60.9 \\
$11-20$ years old & 2 & 3.1 \\
$21-30$ years old & 9 & 14.1 \\
$31-40$ years old & 9 & 14.1 \\
$>40$ years old & 5 & 7.8 \\
\hline
\end{tabular}

Table 2 showes that according to the identification result of P.falciparum species was in 36 respondents $(56.3 \%)$ more than P.vivax species, meanwhile, mix infection was only $10.9 \%$.

Table 2. Distribution of Identification Result of Plasmodium species by Using RDT

\begin{tabular}{lcc}
\hline \multicolumn{1}{c}{ Type of Parasite } & $\mathrm{N}$ & $\%$ \\
\hline P. Falcifarum & 36 & 56.3 \\
$P$. Vivax & 14 & 21.9 \\
Mix & 7 & 10.9 \\
No detected & 7 & 10.9 \\
Total & 64 & 100 \\
\hline
\end{tabular}

Table 3 showes that according to the identification result of Plasmodium species by using giemsa painting removal thick and thin blood drops was found Plasmodium stage in microscopic, which was P.falciparum species with gametocytes in 27 respondents (42\%).

Table 3. Distribution of Identification Result of Plasmodium according to Microscopic Test as

\begin{tabular}{lcc}
\multicolumn{3}{c}{ a Gold Standard } \\
\hline \multicolumn{1}{c}{ Type of Parasite } & N & $\%$ \\
\hline Pf. StdGametosit & 27 & 42.2 \\
Pf. StdCincin & 7 & 10.9 \\
Pv. StdTropozoid & 10 & 15.7 \\
Pv. StdCincin & 2 & 3.1 \\
Pf. StdGametosit + ring & 7 & 10.9 \\
No detected & 11 & 17.2 \\
Total & 64 & 100 \\
\hline
\end{tabular}

Tabel 4 showes that parasitemia distribution according to age group was mostly on the age of 0-10 years old with P. falciparum species, P.vivax species, and Mix Infection.

Table 4. Distribution of Parasitemia according to Age Group

\begin{tabular}{lccc}
\hline \multicolumn{1}{c}{ Age Group (Year) } & P. Falcifarum & P. Vivax & Mix \\
\hline $0-10$ & 23 & 7 & 5 \\
$11-20$ & 0 & 0 & 0 \\
$21-30$ & 3 & 5 & 0 \\
$31-40$ & 5 & 1 & 1 \\
$>40$ years old & 5 & 1 & 1 \\
Total & 36 & 14 & 7 \\
\hline
\end{tabular}


According to sensitivity and specificity test (Table 5) that RDT was a tool that was used to identify the type of parasite species in the diagnosis of malaria in remote and isolated area.

Table 5. Accuracy Rapid Diagnostic Test (RDT)

\begin{tabular}{lccc}
\hline & Microscopic $(+)$ & Microscopic $(-)$ & Total \\
\hline RDT (+) & 53 & 4 & 57 \\
RDT (-) & 0 & 7 & 7 \\
Total & 53 & 11 & 64 \\
\hline
\end{tabular}

$\begin{array}{ll}\text { Sensitivity } & : 100 \% \\ \text { Specificity } & : 63 \% \\ \text { Positive Predictive Value } & : 92.9 \% \\ \text { Negative Predictive Value } & : 100 \% \\ \text { Likelihood ratio of a Positive Test } & : 2.75 \\ \text { Likelihood ratio of a Negative Test } & : 0 \\ \text { Cohen's kappa (Unweighted) } & : 0\end{array}$

\section{DISCUSSION}

This research was a Cross Sectional diaagnostic test, which was conducted in Namrole subdistrict, South Buru Regency, Maluku Province. The samples of this research were 64 people indicated as suffering from malaria, of 64 respondents 7 people were declared negative from malaria after laboratory test. Most sufferers were in age under 1 year old to 10 years old, as many as 39 sufferers or $60.9 \%$. Children aged under 1 year to 10 years old were the most sufferers in this research, this was due that children of that age were still adverse to the exposure of environmental change, and their immunity were relatively weaker than those of adults. Plasmodium falciparum was the most found parasites on children, with the number of plasmodium falciparum as may as 23 sufferers. While 7 others were positively having plasmodium vivax, while 5 of whom were mixed.

Based on the result of malari checking by using RDT instrument, it was known that there were 3 types i.e., P. falciparum, P. vivax, and Mixed. Most detected parasites is P. falciparum 56.3\%, then P. Vivax $21.9 \%$, and mixed $10.9 \%$. After proven with advance test i.e. Microscopic as Gold Standard, it was suggested that 4 results of RDT were not confirmed with microscopic test. Besides, there were 2 samples which was identified with RDT as P. Vivax, however microscopic test suggested that the parasites were P. falciparum std gametocyte.

In Table 5, the accuracy of test with Rapid Diagnostic Test (RDT) instrument proven with microscopic suggested a result that by using $2 \times 2$ table, the sensitivity of RDT instrument was $100 \%$, while the specificity of RDT instrument was $63.3 \%$ for early detection of malaria. Positive predictive value was $92.9 \%$, while negative predictive value was $100 \%$ with positive likelihood ratio of 2.75 , negative likelihood ration was 0 , degree of conformity (Kappa) between RDT and microscopic was 0 .

This research was supported by the research in KeruakCommunity health Centre, East Lombok Regency, suggesting sensitivity value of $100 \%$, specificity of $96.99 \%$, positive likelihood value of $83.2 \%$, and negative predictive value of $100 \%$. It can be concluded that RDT has good reliability validity to be used as diagnostic instrument [17].

Results of research conducted it is known that sensitivity value and specificity value of microscopic were better than RDT in malaria test for pregnant woman [4]. The sensitivity of rapid diagnostic test in this research is very affected by parasite density. Generally, parasite density in rapid diagnostic test $(+)$ and microscopic (+) were relatively higher compared to that of rapid diagnostic test (-) and microscopic [9], [18].

Thus, RDT can be recommended for early detection of malaria, especially i remote, inland, and isolated area, compared to that of microscopic test. Rapid Diagnostic Test instrument (RDT) has benefit in detecting plasmodium rapidly and easily. The lacking of RDT is that it can not determine the amount of prasites in one's blood.

\section{CONCLUSION}

The conclusion based on the results are: 1) The benefit of microscopic as Gold standard is that this instrument has the highest accuracy value for identifying plasmodium species and parasitaemia level calculation, however it must be performed by skilled technicians in conducting diagnosis, 2) Microscopic test 
suggested better result than that of Rapid Diagnostic Test, particularly for low parasites density. Rapid Diagnostic test suggested shortage that can be used as alternative malaria test method, but Rapid Diagnostic test is still very necessary, particularly in areas lacking of laboratory technicians and for surveillance purpose, 3) The benefit of Rapid Diagnostic Test (RDT) was that it could be used in remote and isolated areas to early detect malaria in the effort of conducting malaria diagnosis. Besides, RDT can be recommended and was proven very effective and efficient to be performed in case of Extraordinary Incidents.

\section{ACKNOWLEDGEMENTS}

We would like to thank the malaria patients in Namrole Sub District for their willingness to participate in this study. We gratefully acknowledge the Head and Staffs of Department of Health of South Buru District, Namrole Sub District as well as the Head and Staffs of Namrole Community Health Center (Puskesmas).

\section{REFERENCES}

[1] World Health Organization, “The World Malaria Report,” Geneva, World Health Organization, 2013.

[2] Health Ministry of Indonesia,"Technical Guidelines for Examination of Malaria Parasites. Directorate of controls animal-borne diseases," Jakarta, Health Ministry of Indonesia, 2010.

[3] Achmadi,"Management of Area-Based Diseases Eradication," Jakarta, Publisher Book Kompas, 2005.

[4] Health Ministry of Indonesia,"Regional Health Research (Riskesdas 2007)," Jakarta, Health Ministry of Indonesia, 2007.

[5] World Health Organization,"Malaria elimination. A field manual for low and moderate endemic countries," Geneva, World Health Organization, 2007.

[6] Health Department of Maluku Province, "Health Profile of Maluku Province," 2014.

[7] Health Department of South Buru District,"Health Profile of South Buru District," 2014.

[8] Latuconsina,"Pataheri and Pasuno Initiation Ritual," Naulu tribe, Center Maluku District, 2007.

[9] Siahaan, "Comparative of Rapid Diagnostic Test with Microscopy to Diagnose Malaria Diseases,"Jurnal Kesehatan Masyarakat Nasional,vol/issue: 5(6), 2011.

[10] B. M. Holder, "What is the Function of MSP-1 on the Malaria Merozoit?"Focus, pp. 1-3, 2005.

[11] World Health Organization,"Malaria Rapid Diagnostic Test Performance Results of WHO Product esting of Malaria RDT: Round 1," Geneva, World Health Organization, 2008.

[12] World Health Organization, "Guidelines for The Treatment of Malaria," Geneva, World Health Organization, 2006.

[13] Q. A. Acton, "Issue in Global Pasific Community and Institutional Health," Georgia, Scholarly Edition, 2012.

[14] Q. A. Acton, "Malaria New Insigths for The Health Care Professional," Georgia, Scholarly Edition, 2013.

[15] Brunett G.W.,"CDC Health Information Istitutonal Travel," Oxford,The Yello Book, 2016.

[16] Soedarto,"Malaria, Global Epidemiology of Plasmodium Anopheles on the Management of Malaria Patient," Jakarta, Sagung Seto, 2011.

[17] Arum I. L., et al.,"Diagnostic Test Method Using Imunokromatografi compared with microscopic examination Malaria Plasmodium Falciparum," Indonesian Journal Of Clinical Pathology And Medical Laboratory, 2006.

[18] R. Sinaga,"The Sensitivity and Specificity Assessment of the Rapid Diagnostic Test (RDT) to The Gold Standard of Microscope Slides of Blood for Early Detection of Malaria in Pregnancy," 2006. 